\title{
Testing a new Contrarian Strategy between Hong Kong and the Australian Resources Sector: A Research Note
}

\author{
Santosh Mon Abraham \\ Curtin University, Bentley, Western Australia \\ School of Economics and Finance \\ E-mail: Santosh.monabraham@gmail.com
}

Received: Oct. 1, 2013 Accepted: November 15, $2013 \quad$ Published: January 1, 2014

doi:10.5296/jmr.v6i1.4854 URL: http://dx.doi.org/10.5296/jmr.v6i1.4854

\begin{abstract}
During the financial crisis investment strategies following long only asset allocation methodologies floundered in the wake of a 57\% peak-to-trough decline of the S\&P 500. This paper demonstrates a new strategy that produces strong returns in both up and down markets. A new contrarian/pairs-trading approach using the Johansen (1988) cointegration method was developed and implemented from January 2003 to March 2013 using constituent stocks from the Hang Seng Index and Metals and Mining Index. The strategy produced a return of over $607 \%$ for the period (or an annual return of more than $21 \%$ ). This supports previous research demonstrating the profitability of international arbitrage strategies (for example Abraham, 2013a; and Abraham, 2013b).
\end{abstract}

Keywords: Contrarian, Pairs-Trading, Cointegration

JEL: G14, G15. 


\section{Macrothink}

\section{Introduction}

Figure 1 compares the Hang Seng Index with the Metals and Mining Index from 2007 - 2013. The two indices seem to track each other closely, implying that they may be economically linked with each other. Previous studies have demonstrated that the Chinese and Australian markets are linked through trade, with Australian exports of metals, coal and minerals benefitting both countries (for example Abraham, 2013a; and Abraham, 2013b).

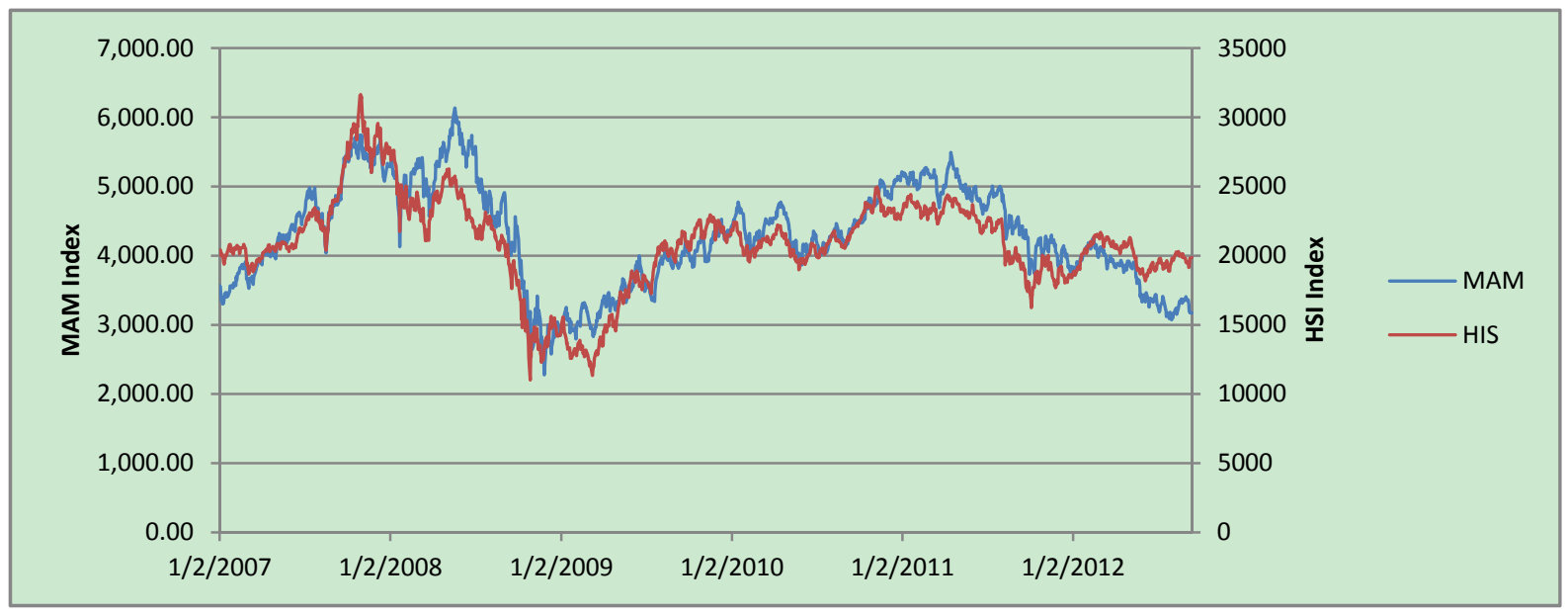

Figure 1. Comparison of the Hong Kong Hang Seng Index and the Australian S\&P/ASX 300 Metals and Mining Index

NOTE: The Hang Seng Index is obtained from Yahoo Finance and the Metals and Mining Index is obtained from Standard and Poors.

The Efficient Market Hypothesis (EMH) is based on the following assumptions (Soares et al, 2005 and Burghardt, 2010);

- investors are rational;

- if they are not fully rational, they act in opposite directions, and cancel each other out; and

- Otherwise, there are many arbitrageurs who will bring prices back to fundamentals.

Critics of the EMH state that people have loss avoidance (Odean, 1998) trade too much (Odean, 1999), which manifests as a failure to divest losing stocks and a preference to sell winning stocks (Shefrin \& Statman, 1985; as cited in Soares et al, 2005 and Burghardt, 2010).

These deviations from rational behavior are due to the following (Soares, et al, 2005 and Burghardt, 2010); 
- individuals are not rational, but rather develop preferences according to Prospect Theory and display loss aversion;

- they put greater weight on recent events;

- Framing effects cause them to form decisions depending on how a problem is presented.

Barberis and colleagues (1998) showed that security prices tend to under-react to new information. Also, over longer time periods, security prices over-react (Soares et al, 2005 and Burghardt, 2010). De Bondt and Thaler (1985) find investors over-reacted to good or bad news, and as a result, winners underperformed and losers outperformed in the following years. Eventually, prices revert to their fundamentals. Barberis and colleagues (1998) base their model on the heuristics of conservatism and representativeness. The typical investor is not fully informed about all securities, and yet the market may reach a state in which prices completely adjust to all information. This is due to the behaviours of marginal investors (Haugen, 2001). These people are well informed analysts, arbitrageurs and traders, who use computer models and databases which provide op to date information on firms. They act on information quickly so that stock prices fully reflect company, industry and economic information (Haugen, 2001). So it is conceivable that stocks are inefficient in the short-term but efficient in the long-term.

The disposition effect, results in under-reaction to economic information, leading to momentum effects (Frazzini, 2006). Securities do not reflect publicly available information in the short-term. Spyrou and colleagues (2007) find short-term investor reaction to extreme shocks in equities show that the market reaction to shocks for large capitalization stocks is efficient. However, for medium and small capitalization stocks the results indicate under-reaction to both positive and negative shocks. Daniel, Hirshleifer and Subrahmanyam (1998) find that investors are overconfident. The subsequent arrival of information that either confirms or disconfirms investor private information leads to further overreaction and return momentum; and reversals in the long run, as investors become aware of their mistakes (Spyrou et al, 2007).

Pairs trading exploit the stocks that are out of equilibrium for short-term time. It works by taking the arbitrage opportunity of temporary anomalies between related stocks which have long-run equilibrium, in which one stock will be overvalued relative to the other stock, by investing in a two-stock portfolio where the overvalued stock is sold and the undervalued stock is bought. The trade is closed out by taking the opposite position of these stocks after the stocks have reached their fundamental value; which is its long-run equilibrium relationship. The profit does not depend on market movements, making it a market-neutral investment strategy (Puspaningrum, 2009). Hong and Susmel (2003) formed a sample of 64 Asian shares that are listed in the U.S. as American depository receipts (ADR) over the period from 1991 to 2000 to examine the pairs underlying domestic shares with their ADRs. Nath (2003) examined 829 U.S. government debt securities over the period from 1994 to 2000. Perlin (2006) studied 100 most liquid stocks from the Brazilian market over 2000 and 
2006. Gatev et al. (2006) analyze a sample of US stocks over 1962 and 2002. These pairs trading approaches demonstrates positive performance (Yuskel et al, 2010).

The cointegration relationship guarantees that the two stocks have a long-run stationary relationship. A linear combination of two I(1) non-stationary time series could form a stationary time series. If this happens, these two I(1) series are cointegrated. This paper utilises the Johansen (1988) methodology. The Johansen's approach uses a vector error-correction model (VECM) so that all variables can be endogenous (Puspaningrum, 2009). The theory of international investing is that international capital markets have independent price behaviours (Solnick et al, 2004). This paper introduces a strategy which profits from the connectedness of international capital markets and also provides a hedge against currency risk. During the financial crisis investment strategies following long only asset allocation methodologies floundered in the wake of a 57\% peak-to-trough decline of the S\&P 500 (Velissaris, 2010). In his recent papers, Abraham (2013a; 2013b) demonstrates that long-short/pairs-trading strategies are profitable, irrespective of market movements.

\section{The Law of One Price strategy (LOP)}

In its absolute form, the PPP condition states that the nominal exchange rate should be proportional to the ratio of the domestic to the foreign price level, i.e.

$$
S_{t}=\alpha+\beta_{0} P_{t}-\beta_{1} P_{t}^{*}+\mu_{t}
$$

$\mathrm{S}_{\mathrm{t}}$ is the nominal exchange rate, $\mathrm{P}_{\mathrm{t}}$ is the Australian resources stock and $\mathrm{P}_{\mathrm{t}}^{*}$ is the CSC stock and $\mu_{\mathrm{t}}$ stands for the regression errors. This is known as a trivariate relationship. The Johansen (1988) cointegration methodology is used to evaluate (1) by implementing a VECM and capturing the residuals of (1). A Signal Index to determine when to enter and exit a trade.

$$
R E S I D \geq E[\mu] \pm \delta \sigma_{\mu t}
$$

The SI is based on the $95 \%$ confidence interval, where $E\left[\mu_{t}\right]=0 \delta=1.96$. Enter the trade if the RESID (the residual) value is greater than $\delta \sigma_{\mu t}$ or less than $-\delta \sigma_{\mu t}$ standard deviations from the mean and exit the trade by reversing positions if the $+/-\delta \sigma_{\mu t}$ standard deviation is less than RESID.

If stocks in the Hang Seng Index and Australian resources stocks are good substitutes for each other they should be priced to the same fundamental value in efficient markets in the long-term. If one of the stocks in one index is mispriced in the short-run, rational investors will take advantage of this mis-pricing by selling the relatively overpriced one and purchasing the relatively under-priced one and earn a profit. Consequently their prices will revert to the fundamental value eventually. There should be a long-run equilibrium and the 
spread between them should be stationary. If they are indeed cointegrated, trading strategies, which exploit the mean reverting property of the spreads between the pairs of stocks, should result in a profit (Abraham, 2013b).

\section{The Abraham Partial Adjustment Model}

The Abraham PAM (Abraham 2013b; 2013c) assumes the long-run equilibrium equation is given by the single-index model:

$$
R_{t}=a+\beta R_{m}+e
$$

Where $R_{t}$ is the target return; $a$ is the excess return; $B$ is the sensitivity of the stock to the market, $\mathrm{R}_{\mathrm{m}}$ is the market return; and e is the residual.

The following hypothesis known as the Abraham PAM is postulated:

$$
\begin{aligned}
& R_{t}-R_{t-1}=\delta\left(R_{t}-R_{t-1}\right) \\
& R_{t}-R_{t-1}=\delta\left(\left(a+\beta R_{m}+e\right)-R_{t-1}\right) \\
& R_{t}=\delta a+\delta \beta R_{m}+(1-\delta) R_{t-1}+\delta e \\
& R_{t}=\delta a+\delta \beta R_{m}+(1-\delta) \beta R_{m_{t-1}}+\delta e
\end{aligned}
$$

Where $R_{t}$ is the return in time period $t, R_{t-1}$ is the return in time period $t-1, \delta$ is the speed of adjustment coefficient and $\mathrm{e}$ is the error term $\mathrm{E}[\mathrm{e}]=0$ and $\mathrm{E} \sim \mathrm{N}\left(0, \sigma^{2}\right)$. When $\delta$ equals 0 there is no adjustment, when $\delta$ equals 1 there is full adjustment and the market is efficient, when $\delta$ is greater than 1 there is an over-reaction to economic information and when $\delta$ lies between 0 and 1 there is partial adjustment or under-reaction to economic information. For more information on the Abraham PAM see Abraham (2013b; 2013c).

\section{Data and Methodology}

The data is the top 33 (by market capitalisation) Australian resources stocks and Hang Seng index and its constituent stocks from 1 January 2003 to 1 March 2013. The weekly data was obtained from Yahoo Finance. Stocks were selected based on their market capitalisation. Missing values were substituted from prices occurring the previous day. There were 532 observations. The transaction cost for Australian and Chinese trades was assumed to be $1.4 \%$. This was based on brokerage data from Australia and China (Hang Seng Investment October 2010; Commsec March 2013). Dividends were assumed to be reinvested. For the LOP strategy the Johansen approach was used. The Australian and Hong Kong stocks were ranked and paired with each other based on their similar speed of adjustment coefficients. The Hong Kong stocks were converted to Australian dollars and transformed into logarithms. 


\section{Results}

Table 1 shows the profitability of the pairs-trading strategy using Hang Seng Index constituent stocks and Australian resource stocks.

Table 1. The Profitability of the LOP strategy implemented using Hong Kong and Australian Stocks

\begin{tabular}{|c|c|c|c|c|c|c|}
\hline STOCK & SPEED & MCAP(mil) & STOCK & SPEED & MCAP(mil) & PROFIT (\%) \\
\hline WSA.AX & 0.645269 & 574.78 & 0019.HK & 179.8094 & HK $\$ 134,615.00$ & 120.7602 \\
\hline TRY.AX & 0.639092 & 173.96 & 0101.HK & 146.1484 & HK $\$ 107,493.50$ & 144.9203 \\
\hline AAI.AX & 0.393709 & 8500 & 0386.HK & 20.82513 & HK\$682,275.81 & \\
\hline SPH.AX & 0.393499 & 676.63 & 0941.HK & 11.48799 & $\mathrm{HK} \$ 1,628,286.00$ & \\
\hline MDL.AX & 0.390822 & 275.68 & 0293.HK & 6.209212 & HK\$64,042.99 & -461.528 \\
\hline SIR.AX & 0.381389 & 788.42 & 0001.HK & 5.257588 & HK $\$ 282,572.09$ & \\
\hline AGG.AX & 0.37959 & 1831 & 0017.HK & 5.231588 & HK\$61,604.92 & \\
\hline SGM.AX & 0.379489 & 1936.85 & 1880.HK & 3.584263 & $\mathrm{HK} \$ 75,317.70$ & \\
\hline NCM.AX & 0.379333 & 14399.05 & 0004.HK & 3.499691 & HK $\$ 179,989.59$ & 1163.096 \\
\hline OGC.AX & 0.377127 & 1362.91 & 1044.HK & 3.459448 & HK $\$ 112,302.30$ & 10.6397 \\
\hline RIO.AX & 0.376242 & 85933.67 & 1199.HK & 3.100271 & HK\$30,987.14 & 217.6881 \\
\hline IRN.AX & 0.374217 & 409.07 & 0012.HK & 2.85234 & HK $\$ 119,565.50$ & -29.59 \\
\hline GRR.AX & 0.369982 & 219.73 & 0083.HK & 2.521418 & HK $\$ 63,285.39$ & \\
\hline RRL.AX & 0.362054 & 1878.68 & 0267.HK & 2.501453 & HK $\$ 43,355.40$ & \\
\hline IGR.AX & 0.357345 & 485.9 & 0494.HK & 2.46905 & HK $\$ 84,105.61$ & 152.1506 \\
\hline KCN.AX & 0.355858 & 531.4 & 0144.HK & 2.203772 & HK $\$ 71,880.08$ & 1284.631 \\
\hline IMD.AX & 0.355241 & 271.51 & 0762.HK & 2.01776 & HK\$278,195.91 & -144.983 \\
\hline SDL.AX & 0.346122 & 645.14 & 0023.HK & -0.3139 & HK\$75,668.32 & -3197.73 \\
\hline RSG.AX & 0.343863 & 729.91 & 0027.HK & -0.51194 & HK $\$ 288,185.31$ & \\
\hline CDU.AX & 0.334394 & 663.59 & 0005.HK & -0.83169 & HK $\$ 1,578,887.00$ & -30.842 \\
\hline EVN.AX & 0.328789 & 902.82 & 1109.HK & -0.94384 & HK $\$ 112,064.70$ & \\
\hline SBM.AX & 0.310326 & 514.92 & 0388.HK & -1.52953 & HK $\$ 151,691.00$ & \\
\hline BSL.AX & 0.309963 & 2651.66 & 0003.HK & -1.73144 & HK $\$ 170,353.30$ & \\
\hline ARI.AX & 0.309798 & 1020.4 & 2388.HK & -2.08055 & HK\$263,262.19 & 6.8022 \\
\hline GDO.AX & 0.307763 & 339.97 & 0011.HK & -2.23633 & HK $\$ 240,127.50$ & \\
\hline BHP.AX & 0.296733 & 161632 & 0322.HK & -2.36752 & HK $\$ 128,428.20$ & \\
\hline IGO.AX & 0.294202 & 859.34 & 0013.HK & -2.50434 & HK $\$ 445,095.91$ & 1596.856 \\
\hline PNA.AX & 0.284723 & 1406.99 & 0006.HK & -3.94668 & HK $\$ 131,470.50$ & 8696.639 \\
\hline GBG.AX & 0.266787 & 283.51 & 0688.HK & -5.88987 & HK $\$ 178,163.00$ & 292.8458 \\
\hline MGX.AX & 0.266618 & 512.57 & 0002.HK & -6.07192 & HK $\$ 178,163.00$ & -133.785 \\
\hline AQP.AX & 0.254097 & 316 & 0016.HK & -8.8213 & HK\$264,233.41 & \\
\hline OZL.AX & 0.252541 & 1440 & 0857.HK & -8.92129 & $\mathrm{HK} \$ 1,775,247.00$ & \\
\hline LYC.AX & 0.151946 & 1009.81 & 0291.HK & -13.0757 & HK\$62,488.48 & \\
\hline
\end{tabular}

NOTE: 'STOCK' represents the Hang Seng Index constituent stock and the Australian resources stock; 'SPEED' represents the speed of adjustment coefficient; 'MCAP' represents market capitalization and 'PROFIT' represents the percentage profit from the pairs-trading strategy. 
The results show that small cap pairs are more profitable than large cap pairs. Hong Kong stocks tend to over-react. This over-reaction occurs towards the target or away from the target. For reactions in the opposite direction of the target, the conclusion is that the stocks are adjusting very rapidly away from their fundamental values. These inefficiencies lead to profitable arbitrage opportunities, except in the instances of $0016 \mathrm{HK}, 0857 \mathrm{HK}$, and $0291 \mathrm{HK}$, where mispricing continues without converging to its fundamental value. The most profitable pair was PNA.AX/0006.HK, and the least profitable was SDL.AX/0023.HK.

\section{Conclusion}

Unlike previous international arbitrage studies between China and Australia (for example, Abraham, 2013a; Abraham 2013b), which were hypothetical, this strategy between Hong Kong and Australia may be fully implemented. This supports the research of De Bondt and Thaler (1985) who proposed that small cap stocks were more profitable than large caps and that small caps tended to over-react to new information.

\section{References}

Abraham, S.M. (2013a). Testing International Momentum Strategies between Chinese and Australian Financial Markets. International Journal of Financial Research, 5, 1, 1-10. http://dx.doi.org/10.5430/ijfrv5n1p1

Abraham, S.M. (2013b). The Profitability of Contrarian Stock Pairs Identified Using a Partial Adjustment Model: An Evaluation of Chinese and Australian Stocks. International Journal of Economics and Finance, 5, 11: 82-94. http://dx.doi.org/10.55539/ijefv5n11p82

Abraham, S.M. (2013c). Testing for Over-reaction and Under-reaction in Chinese Shanghai Composite Index Constituent Stocks and Australian Resource Stocks. International Journal of Economics and Finance, 5(10), 51-57. http://dx.doi.org/10.55539/ijefv5n10p51

Burghardt, M. (2010). Retail Investor Sentiment and Behavior - an Empirical Analysis. PhD Dissertation Universität Karlsruhe.

De Bondt, W. F. M. \& Thaler, R. (1985). Does The Stock Market Over-react?The Journal of Finance, 40(3), 793-805. http://dx.doi.org/10.1111/j.1540-6261.1985.tb05004.x.

Frazzini, A. (2006). The Disposition Effect and Under-reaction to News. The Journal of Finance, 61(4), 2017-2046. http://dx.doi.org/10.1111/j.1540-6261.2006.00896.x.

Haugen, R.A. (2001). Modern Investment Theory, $5^{\text {th }}$ Edition, Upper Saddle River, New Jeresy: Pearson/Prentice Hall.

Johansen, S. (1988). Statistical Analyses of Cointegrating vectors. Journal of Economic Dynamics and Control, 12, 231-54.

Puspaningrum, H., Lin, Y. X., \& Gulati, C. (2009). Finding the Optimal Pre-set Boundaries for Pairs Trading Strategy Based on Cointegration Technique, Centre for Statistical and Survey Methodology, University of Wollongong, Working Paper 21-09, 2009,25p. http://ro.uow.edu.au/cssmwp/41 


\section{Macrothink}

Journal of Management Research

ISSN 1941-899X 2014, Vol. 6, No. 1

Soares, J.V., \& Serra, A.P. (2005). Over-reaction and Underreact ion: Evidence for the Portuguese

StockMarket.http://www.fep.ip.16/conferencias/pfn2006/2010/Conference28/Papers/577.pdf

Solnick, B., \& McLeavey, D. (2004). International Investments, $5^{\text {th }}$ Edition, Upper Saddle River, New Jersey: Pearson Education Inc.

Spyrou, S., Kassimatis, K., \& Galariotis, E. (2007). Short-term Over-reaction, Under-reaction and Efficient Reaction: Evidence from the London Stock Exchange. Applied Financial Economics, 17, 221-235. http://dx.doi.org/10.1080/09603100600639868.

Velissaris, J. (2010). Diversified Statistical Arbitrage: Dynamically combining mean reversion and momentum investment strategies. Submitted for Review to the National Association of Active Investment Managers

(NAAIM) for the Wagner Award Competition 2010. (C) EuroJournals Publishing, Inc. http://www.eurojournals.com/MEFE.htm

Yuskel, A., \& Muslumov, A. (2010). Pairs Trading with Turkish Stocks. Middle Eastern Finance and Economics, 7, 38-54. 